BMJ Open Sport \& Exercise Medicine

\section{Dysnatremia among runners in a half marathon performed under warm and humid conditions}

To cite: Martinez-Cano JP, Cortes-Castillo V Martinez-Villa J, et al. Dysnatremia among runners in a half marathon performed under warm and humid conditions. BMJ Open Sport \& Exercise Medicine 2018:4:e000351. doi:10.1136/ bmjsem-2018-000351

Accepted 23 May 2018
Check for updates

${ }^{1}$ Orthopaedic Surgery

Department, Fundación Valle de Lili, Cali, Colombia

${ }^{2}$ Facultad de Ciencias de la Salud, Universidad Icesi, Cali, Colombia

${ }^{3}$ Center for Clinical Investigations, Fundación Valle del Lili, Cali, Colombia

Correspondence to Dr Juan Pablo Martinez-Cano; jpmartinezc@gmail.com

\section{ABSTRACT}

Background Dysnatremia has been associated with sports activity, especially long-distance running and endurance sports. High fluid intake is associated with hyponatremia. This study aims to evaluate dysnatremia and risk factors in half-marathon runners under warm and humid environmental conditions.

Methods A cross-sectional study was performed among randomly selected runners in the 2017 Cali half marathon. Runners on diuretic therapy or with a known history of kidney disease were excluded. Participants went through a 2-day assessment. Previous medical history, training history, body mass index and running history were determined in the first assessment. Symptoms of dysnatremia and level of fluid consumption during the race were registered during the second assessment and postrun blood sampling for serum [Na+] was also undertaken. Results 130 runners were included in the study. The complete 2-day assessment was performed on 81 participants $(62 \%)$ that were included in the final analysis. No cases of hyponatremia were found; instead, there were six cases of asymptomatic hypernatremia (7.4\%). This hypernatremia had a statistically significant association with lower frequency $(p=0.01)$ and volume of fluid intake during the race (water: $p=0.02$, Gatorade: $p=0.04$ ).

Conclusion Hyponatremia has been associated with high fluid intake in races performed under cool weather, such as the Boston Marathon during spring. In contrast, hypernatremia was found in a half marathon in warm and humid weather, which was associated with lower volume and frequency of fluid intake, suggesting that under warm and humid conditions, a median fluid intake of $900 \mathrm{~mL}$ during the race could prevent this event.

\section{INTRODUCTION}

An adequate fluid and electrolyte balance is of great importance for metabolic regulation, as water and electrolytes provide the medium for physiological reactions and determine the maintenance of both an adequate blood volume and integrity of the cardiovascular system as a whole. ${ }^{1-3}$

Sodium is one of the most important electrolytes involved in the homeostasis of the human body: as the major extracellular cation, it mediates the regulation of cell

\section{What are the new findings}

Lower fluid intake is associated with hypernatremia in runners of a half marathon in warm and humid weather.

- $7.4 \%$ was the incidence of hypernatremia during the race.

- A median fluid intake of $900 \mathrm{~mL}$ protects against hypernatremia in this type of race.

How might it impact on clinical practice in the near future

Runners could prevent dysnatremia when running a half marathon

- Fluid intake may vary depending on the length and weather conditions of the race.

- Runners could have a recommended range of fluid intake during a race.

volume, transport across the cell membrane, electric potential and cell signalling. The normal range for blood sodium is between 135 and 145 milliequivalents per litre $(\mathrm{mEq} / \mathrm{L}){ }^{1}$ Dysnatremias are values that fall outside this range (either hyponatremia or hypernatremia) and either can cause cellular dysfunction and systemic symptoms. ${ }^{3}$

Under optimal functioning, renal and hormonal systems maintain the plasma osmolality within tight limits, reflecting the physiological importance of osmolality regulation for cell volume and function, as previously mentioned. ${ }^{3}$ Exercise represents a situation of stress that can lead to electrolyte imbalance and the body has mechanisms to defend itself when faced to this, such as the ability to redistribute water and electrolytes within its fluid compartments, providing a reservoir to minimise the effects of water deficit or electrolyte imbalances, ${ }^{4-7}$ and the hormonal secretion of antidiuretic hormone $(\mathrm{ADH})$, which regulates the secretion and reabsorption of electrolytes, and stimulates the thirst centre to ensure an adequate fluid 
intake during exercise. ${ }^{8}$ These mechanisms can, however, fail; for athletes, high-endurance competitions represent a higher risk for such failures. ${ }^{9-11}$

In athletic competitions, acute hypernatremia and dehydration can present as a result of water loss through sweat associated with low or insufficient fluid intake. ${ }^{9} 1012$ This is a state of hyperosmolality, hence it induces water movement from cells into the extracellular compartment, which is especially important for the central nervous system as it may cause cell shrinkage, leading to symptoms such as nausea, vomiting, confusion, seizures, muscle weakness, muscle twitching and even death. Although it is uncommon for hypernatremia to progress to serious complications in such settings, ${ }^{13}$ it has occasionally been associated with collapse. ${ }^{1014}{ }^{15}$ On the other hand, exercise-associated hyponatremia is usually the result of excessive water intake. ${ }^{16-19}$ In most cases, it presents with no symptoms or mild symptoms of weakness, dizziness, nausea and vomiting, but in cases involving a major drop in serum sodium levels, there is higher risk of a fast inflow of water into the cells leading to oedema which, in the central nervous system, is manifested as altered mental status, seizures and even death. ${ }^{3} 1020$

The relationship between different hydroelectrolytic imbalances and exercise has been assessed in several studies. Almond $e t a l^{21}$ found hyponatremia in $13 \%$ of the runners in the Boston Marathon, which was associated with a higher intake of liquids during the race. ${ }^{21}$ Severac et $a l^{22}$ reported the case of a 42-year-old woman who developed severe hyponatremia (serum [Na+] of $123 \mathrm{mEq} / \mathrm{L}$ ) after running an Ironman race. She had symptoms of cephalea, nausea and confusion, which rapidly evolved into neurological deterioration and ventilatory failure; she did, however, respond well to an adequate sodium correction and fluid replenishment. ${ }^{22}$

On the other hand, Au-Yeung et al. ${ }^{13}$ measured serum sodium levels in marathon runners in Hong Kong, finding a higher incidence of hypernatremia (12.9\%) than hyponatremia $(0.4 \%)$. Increased sodium levels were more prevalent in runners who had a lower fluid intake during the race and those with better physical training prior to the marathon. No symptomatic dysnatremia was found. ${ }^{13}$ Hew-Butler et $a l^{23}$ evaluated the presence of dysnatremia in the Comrades Marathon, finding hypernatremia in $45 \%$ of the runners. ${ }^{23}$

For the half-marathon distance, there is a report of severe hyponatremia after running a half marathon. ${ }^{24}$ There is also a study of Del Coso et $a l^{25}$ comparing serum sodium concentration values before and after the race. In this study, there was a similar increase in serum sodium for both marathoners (from $140.0 \pm 0.9$ to $143.7 \pm 1.6$ $\mathrm{mmol} / \mathrm{L}, \mathrm{p}<0.05$ ) and half-marathoners (from $140.7 \pm 1.2$ to $142.3 \pm 1.7 \mathrm{mmol} / \mathrm{L}, \mathrm{p}<0.05$ ) at the end of the race, with no statistically significant difference between both group of runners. ${ }^{25}$

The purpose of this study is to assess the incidence of dysnatremia in half-marathon runners, and was carried out in a warm and humid city in South America located
$1000 \mathrm{~m}$ above sea level, and to correlate these findings with possible risk factors such as body mass index (BMI), fluid consumption, gender, age and time taken to complete the race. The hypothesis is that fluid intake correlates with dysnatremia in half-marathon runners under these conditions.

\section{MATERIALS AND METHODS Study design and study population}

A cross-sectional study was performed among runners in the Cali half marathon (28 May 2017). Eligible participants included men and women over the age of 18 who were going to run the half marathon (21K). Participants on diuretic therapy or with a known history of kidney disease were excluded.

The recruitment process was carried out randomly at the Race Kit Pickup site the day before, which was a mandatory stop for every runner. After receiving information and addressing any doubts the potential participants might have had, the eligible participants signed a written consent and completed a survey regarding demographic information, running experience and training information. Afterwards, they were evaluated by a physician who registered medical history, weight and height..

A tent was set up at the finish line, where participants were instructed to arrive as soon as completing the race for a physical examination and to assess the presence of any symptoms such as confusion, muscle weakness, spasms, cramps, headache, dyspnoea, dizziness, nausea and vomiting. Information about fluid consumption during the race was collected through a questionnaire. Hydration stations were distributed through the race every $3 \mathrm{~km}$ and included water and Gatorade supply. Volume capacity of cups used to distribute sport drink and water in hydration stations was measured previously, to help in the process of calculating with each participant their fluid intake during the race.

Participants were seated during this interview process and a blood sample was taken from capillary blood in their right index finger. These blood samples were collected within the first 20 min after finishing the race and were immediately processed by qualified health personnel from Fundación Valle del Lili, using i-STAT (Abbott) devices to measure serum sodium levels. These devices were previously calibrated with a reportable range between 100 and $180 \mathrm{mmol} / \mathrm{L}$.

Attendance at the second assessment was encouraged by means of providing a comfortable space to rest, with a selection of beverages and fruits after completing the assessment. There was also an active search for the enrolled participants at the finish line by 10 different people, who showed them their way to the tent.

\section{Independent variable}

Dysnatremia was diagnosed when a serum sodium concentration outside the reference range of 135-145 $\mathrm{mmol} / \mathrm{L}$ was found. Values below and above this range 
were considered hyponatremia and hypernatremia, respectively.

\section{Dependent variables}

BMI, fluid consumption during the race, frequency of fluid consumption, age, gender, total time elapsed to complete the race and the presence of symptoms of dysnatremia, such as confusion, muscle weakness, spasms, cramps, headache, dyspnoea, dizziness, nausea and vomiting.

\section{Statistical analysis}

Stata V.12 was used for statistical analysis. Descriptive statistics were used to calculate the incidence of hypernatremia and to present the demographic characteristics of runners. During the analysis, t-tests, $\chi^{2}$ and Fisher's exact test were used to evaluate the associations between other variables and hypernatremia, considering $p$ values of $\leq 0.05$ to be significant. Prior to the study, sample size calculations were made with a $5 \%$ alpha error and $80 \%$ power, giving an estimated sample size of 96 runners for an expected incidence of hyponatremia of $7 \%$.

\section{RESULTS}

There were 2105 runners registered for the race. A total of 130 runners were included in the study and went through the first assessment. Eighty-one completed the post-run assessment, giving a $62 \%$ follow-up rate. Most participants were men (73\%), with a mean age of 41.3 years (table 1). The weather during the race consisted of temperatures between $22^{\circ} \mathrm{C}$ and $-27^{\circ} \mathrm{C}\left(72-80^{\circ} \mathrm{F}\right)$ and a humidity of $76 \%-95 \%$.

Table 1 shows the baseline characteristics of participants by gender, showing a trend towards male participants being older than female participants and showing statistically significant differences in the number of previous half marathons run, showing greater experience in such races in the female group.

Table 2 shows the baseline characteristics for the runners who completed the 2-day evaluation and runners who were not evaluated for a second time after finishing the race. Runners reporting at the finish line had more experience of running half marathons and had a slightly

Table 1 Baseline characteristics of 2017 half-marathon runners in Cali, Colombia $(n=81)$

\begin{tabular}{|c|c|c|c|}
\hline Sex distribution (\%) & Men n=59 (72.8) & $\begin{array}{l}\text { Women } n=22 \\
(27.2)\end{array}$ & $P$ values \\
\hline Age, years (SD) & $41.6(12.5)$ & $40.2(12.7)$ & 0.89 \\
\hline $\begin{array}{l}\text { Body mass index } \\
\text { (SD) }\end{array}$ & $24.3(2.4)$ & $24(2.4)$ & 0.07 \\
\hline $\begin{array}{l}\text { Previous half } \\
\text { marathons, } n \text { (IQR) }\end{array}$ & $3(1-10)$ & $4(2-6)$ & 0.05 \\
\hline $\begin{array}{l}\text { Years running, } \mathrm{n} \\
\text { (IQR) }\end{array}$ & $3(2-11)$ & $4.5(3-8)$ & 0.45 \\
\hline $\begin{array}{l}\text { Expected race time, } \\
\text { min (IQR) }\end{array}$ & $110(100-120)$ & $125(113-135)$ & 0.13 \\
\hline
\end{tabular}

Table 2 Comparing runners reporting and not reporting at finish line

\begin{tabular}{|c|c|c|c|}
\hline Characteristic & $\begin{array}{l}\text { Reporting at } \\
\text { finish line } n=8\end{array}$ & $\begin{array}{l}\text { Not reporting at } \\
\text { finish line } n=49\end{array}$ & $P$ values \\
\hline Male sex (\%) & 72.8 & 73.5 & 0.55 \\
\hline Age, years (SD) & $41.25(12.47)$ & $38.2(10.7)$ & 0.25 \\
\hline $\begin{array}{l}\text { Body mass index } \\
\text { (SD) }\end{array}$ & 24.05 (2.36) & $24.7(3.1)$ & 0.03 \\
\hline $\begin{array}{l}\text { Previous half } \\
\text { marathons, } n \text { (IQR) }\end{array}$ & $4(1-6)$ & $3(1-5)$ & $<0.01$ \\
\hline $\begin{array}{l}\text { Years running, } n \\
\text { (IQR) }\end{array}$ & $4(2-10)$ & $4(2-7)$ & 0.62 \\
\hline $\begin{array}{l}\text { Expected race } \\
\text { time, min (IQR) }\end{array}$ & $113(105-130)$ & $120(120-135)$ & 0.05 \\
\hline
\end{tabular}

lower BMI. Otherwise, both groups were very similar to each other. When comparing the mean expected race time $(116.3 \pm 18.5 \mathrm{~min})$ with the real race time $(120.0 \pm 19.5$ $\min )$, results were very similar $(\mathrm{p}=0.22)$.

Table 3 shows the relationship between median serum sodium concentration and symptoms. There were no cases of symptomatic runners with dysnatremia. These symptoms were, however, associated with higher serum sodium concentrations, with no statistically significant differences. Nevertheless, since the frequency was very low, the strength of power for the association is limited.

At the end of the race, runners had a mean serum sodium concentration of $142.6 \pm 2.3 \mathrm{mmol} / \mathrm{L}$. No cases of hyponatremia were found: instead, there were six cases of hypernatremia in this study $(7.4 \%)$. Table 4 shows the association between hypernatremia, baseline characteristics and fluid intake during the race. Participants with hypernatremia had a statistically significant association with lower fluid volume intake (water: $\mathrm{p}=0.017$, Gatorade: $\mathrm{p}=0.038$ ) and lower frequency of fluid intake during the race $(p=0.012)$. There was no association with gender, $\mathrm{BMI}$, race time or age.

\section{DISCUSSION}

The results obtained in our study show how endurance sports can relate to different sodium disorders. Previous studies in runners have shown associations with both hypernatremia and hyponatremia in runners. Hyponatremia has been shown to be associated with

Tabel 3 Relationship between seric sodium values and symptoms

\begin{tabular}{llll}
\hline \multirow{2}{*}{$\begin{array}{l}\text { Adverse events } \\
\text { (n) }\end{array}$} & \multicolumn{2}{l}{ Serum sodium median (IQR) } & \\
\cline { 2 - 3 } & Yes & No & P values \\
\hline Nausea (1) & 145 & $142(141-144.5)$ & 0.24 \\
\hline Confusion (2) & $144.5(143-146)$ & $142(141-145)$ & 0.18 \\
\hline Dizziness (2) & $144.5(143-146)$ & $142(141-145)$ & 0.18 \\
Dyspnoea (1) & 145 & $142(141-144.5)$ & 0.24 \\
\hline
\end{tabular}


Table 4 Association of hypernatremia with age, gender, body mass index and fluid intake.

\begin{tabular}{|c|c|c|c|}
\hline & $\begin{array}{l}\text { Hypernatremia } \\
(n=6)\end{array}$ & $\begin{array}{l}\text { No } \\
\text { hypernatremia } \\
(n=75)\end{array}$ & $P$ values \\
\hline Age, years (SD) & 46.7 (14.2) & 40.8 (12.3) & 0.33 \\
\hline \multicolumn{4}{|l|}{ Sex } \\
\hline Male, n (\%) & $5(8.5)$ & $54(91.5)$ & 0.49 \\
\hline Female, n (\%) & $1(4.5)$ & $21(95.4)$ & \\
\hline $\begin{array}{l}\text { Body mass index } \\
\text { (SD) }\end{array}$ & $22.8(9)$ & $24.1(2.4)$ & 0.13 \\
\hline $\begin{array}{l}\text { Water intake, mL } \\
\text { (IQR) }\end{array}$ & $162.5(0-700)$ & $800(600-1200)$ & 0.02 \\
\hline $\begin{array}{l}\text { Sport drink with } \\
\text { electrolyte intake, } \\
\text { mL (IQR) }\end{array}$ & $30(0-80)$ & $80(40-120)$ & 0.04 \\
\hline
\end{tabular}

Percentage of

water loading in

total fluid intake,

\% (IQR) $\quad 86.5(0-100) \quad 92(87-95) \quad 0.77$

Race time, min

(IQR)

$103.5(98-116) \quad 119(105-132) \quad 0.06$

Distance between

fluid intake, $\mathrm{km}$

$\begin{array}{llll}(\mathrm{IQR}) & 7.5(3-21) & 3(3-4) & 0.01\end{array}$

overhydration, a low level of training before the race and a longer time to finish the marathon. ${ }^{9} 1119$

\section{Incidence and risk factors}

An incidence of hypernatremia of $7.4 \%$ was found and no cases of hyponatremia, which differs from the results found by Almond et $a l^{21}$ in the Boston Marathon, where hyponatremia was found at an incidence of $13 \%$. These contrasting results could be attributed to weather differences, as the temperature and humidity registered the day of the half marathon of Cali were higher than those of a typical Boston spring, which can lead to greater dehydration in a shorter time. In addition, since the Boston marathon is longer, the intake of liquids is more prolonged, a situation that could lead to dilutional hyponatremia. Indeed, the hypernatremia found in our study was related to a lower fluid intake during the race. ${ }^{19}$

In the study conducted in Hong Kong by Au-Yeung et al (2010), hypernatremia was found in $12.9 \%$ of runners. ${ }^{11}$ In this study, hypernatremia was found in those participants who had a lower intake of fluids during the race, whether it was water or sports drink containing electrolytes. In general, the total fluid intake for runners was much lower than that recorded in previous studies, possibly explaining why there were no cases of dilutional hyponatremia found as a consequence of the intake of large amounts of fluids. ${ }^{9} 1119$

These results are consistent with previous literature. Hypernatremia is more frequent than hyponatremia in runners, either in $21 \mathrm{~K}, 42 \mathrm{~K}$ or even $250 \mathrm{~K}$ races, ${ }^{8911}$ though there are no previous studies of this kind in a warm and humid environment. However, Mohseni $e t a l^{26}$ measured serum sodium for runners of a half marathon before and after the race. Their study showed a decrease in half-marathon hyponatremic runners from $6.0 \%$ pre-race to $3.8 \%$ post-race, with an increase in the mean serum sodium from 137.9 (4.3) to 140.5 (3.8) mmol/L. ${ }^{26}$ These results are in the same direction of our study, showing a mean increase in serum sodium concentration for runners.

In our study, the median intake of fluids (either pure water or sport beverages with electrolytes) for the group of runners without hypernatremia was $890 \mathrm{~mL}$, suggesting that fluid intake during a half marathon, of around 900 $\mathrm{mL}$, may be protective against hypernatremia.

\section{Limitations}

There are some limitations in this study. For instance, fluid consumption was calculated based on the number of hydration stations along the race, the serving size and the number of servings that runners could recall, making this data prone to some degree of inaccuracy. Since this limitation applies to all runners and is not exclusive to the group with hypernatremia, it is assumed that there might be no bias of the information in any certain direction. Another limitation was related to sample size calculations, which were made on the basis of aiming to find the incidence of hyponatremia and not hypernatremia. Nevertheless, the percentage of hypernatremia found was around $7 \%$, which was the same value used for sample size calculations. Unfortunately, due to the loss of follow-up presented, the final sample was of only 81 runners, less than the 96 participants initially suggested as a sample size.

A higher follow-up rate would be desirable, but it represents a challenge due to the logistics required to guarantee assistance at the assessment after crossing the finish line, especially when it involves blood sampling; the participants usually want to go and rest as soon as possible after their effort. Nevertheless, taking into account these circumstances, a follow-up of $62 \%$ is considered a good result and is similar to the percentages obtained in other studies of this kind, such as the $64 \%$ follow-up for the Boston Marathon study. On the other hand, when comparing runners who completed the 2-day evaluation and runners lost to follow-up, both groups were very similar, having only slight differences in terms of experience and BMI. These variables showed no association with hypernatremia in the study and, therefore, this loss of follow-up is not considered to have significantly affected the outcome.

\section{CONCLUSION}

This study complements the one conducted in the 2002 Boston Marathon by Almond et $a l,{ }^{21}$ which showed the presence of hyponatremia associated with a high intake of liquids in cold weather during spring. Our findings concur with the direction of the Boston Marathon results. This is a half marathon in the tropics, with warm 
and humid conditions that led to hypernatremia in $7 \%$ of the runners, which in turn was associated with lower frequency and total liquid intake.

Dysnatremia is common in high-endurance activities, such as half and full marathons. Although usually mild, they can be severe and life threatening, and so it is important to aim at their prevention, mostly through recommendations regarding fluid intake and adequate training. Nevertheless, suggestions for the former preventative measure seem to need to take into consideration environmental factors. The results found in this study suggest that under warm and humid conditions, an average of $900 \mathrm{~mL}$ of fluid intake might be sufficient during a half marathon to ensure adequate sodium levels. More studies like these, with greater samples, are required to establish a better a hydration range, which, in turn, could lead to the development of guidelines and recommendations for runners and high-endurance athletes.

Acknowledgements Gilberto Parra (race director) and 'Juancho Correlón' team for their permission to make part of the race and their help with logistics during the field work of the study. Laura Ibarra, María Alejandra Muñoz and Janio Andrés Cuadros, medical students from ICESI University, for their help with data collection and recruitment. Dr Helen Reina and Dr María Fernanda Hernandez-Amaris for the copyediting of this manuscript. María Camila Giraldo, María Camila Londoño, Sebastián Torres, Katherine Ramirez, Jennifer Sánchez and Jessica Delgado, physiotherapy students from 'Escuela Nacional del Deporte', for their help with physical therapy at the end of the race for participants from the study. Andres Castro, statistician, for his help in data analysis. María Isabel Sánchez from the communications office and Harold Londoño from the center of clinical investigations at Fundación Valle del Lili, for their help with logistics.

Contributors JPM-C: original idea, study design, grant application, data collection, data analysis, drafting and writing manuscript, final approval. VC-C: study design, data collection, drafting and writing manuscript, final approval. JM-V: study design, data collection, drafting and writing manuscript, final approval. JCR: study design, data collection, drafting and writing manuscript, final approval. JPU: data collection, data analysis, drafting and writing manuscript, final approval.

Funding ICESI University and Fundación Valle del Lili, Cali, Colombia.

Competing interests None declared.

Patient consent Parental/guardian consent obtained.

Ethics approval This study was approved and supervised by the Ethical Committee in Biomedical Research of Fundación Valle del Lili (approval no. 1183).

Provenance and peer review Not commissioned; externally peer reviewed.

Data sharing statement This study includes all relevant information from the study. If readers need additional information, this can be requested to the corresponding author.

Open access This is an Open Access article distributed in accordance with the Creative Commons Attribution Non Commercial (CC BY-NC 4.0) license, which permits others to distribute, remix, adapt, build upon this work non-commercially, and license their derivative works on different terms, provided the original work is properly cited and the use is non-commercial. See: http://creativecommons.org/ licenses/by-nc/4.0/

(c) Article author(s) (or their employer(s) unless otherwise stated in the text of the article) 2018. All rights reserved. No commercial use is permitted unless otherwise expressly granted.

\section{REFERENCES}

1. Terry J. The major electrolytes: sodium, potassium, and chloride. $J$ Intraven Nurs 1994:17:240-7.

2. Best $\mathrm{CH}$, Taylor NB, West JB. Best and Taylor's physiological basis of medical practice. Baltimore: Williams \& Wilkins, 1991:xxxi, 1,170 p. p.

3. Rose BD, Post TW. Clinical physiology of acid-base and electrolyte disorders. 5th edn. New York: McGraw-Hill Medical Pub. Division, 2001:x, 992 p. p.

4. Rothwell SP, Rosengren DJ. Severe exercise-associated hyponatremia on the Kokoda Trail, Papua New Guinea. Wilderness Environ Med 2008;19:42-4.

5. Sanchez LD, Corwell B, Berkoff D. Medical problems of marathon runners. Am J Emerg Med 2006;24:608-15.

6. Agrawal V, Agarwal M, Joshi SR, et al. Hyponatremia and hypernatremia: disorders of water balance. $J$ Assoc Physicians India 2008;56:956-64.

7. Danz M, Pöttgen K, Tönjes PM, et al. Hyponatremia among triathletes in the Ironman European Championship. N Engl J Med 2016;374:997-8.

8. Cairns RS, Hew-Butler T. Incidence of exercise-associated hyponatremia and its association with nonosmotic stimuli of arginine vasopressin in the GNW100s ultra-endurance marathon. Clin J Sport Med 2015;25:347-54.

9. Felig $\mathrm{P}$, Johnson $\mathrm{C}$, Levitt $\mathrm{M}$, et al. Hypernatremia induced by maximal exercise. JAMA 1982;248:1209-11.

10. Krabak BJ, Lipman GS, Waite BL, et al. Exercise-associated hyponatremia, hypernatremia, and hydration status in multistage ultramarathons. Wilderness Environ Med 2017;28:291-8.

11. Rosner MH, Kirven J. Exercise-associated hyponatremia. Clin J Am Soc Nephrol 2007:2:151-61.

12. Lara B, Gallo-Salazar C, Puente C, et al. Interindividual variability in sweat electrolyte concentration in marathoners. J Int Soc Sports Nutr 2016;13:31.

13. Au-Yeung KL, Wu WC, Yau WH, et al. A study of serum sodium level among Hong Kong runners. Clin J Sport Med 2010;20:482-7.

14. Siegel AJ, d'Hemecourt P, Adner MM, et al. Exertional dysnatremia in collapsed marathon runners: a critical role for point-of-care testing to guide appropriate therapy. Am J Clin Pathol 2009;132:336-40.

15. Siegel AJ, Januzzi J, Sluss P, et al. Cardiac biomarkers, electrolytes, and other analytes in collapsed marathon runners: implications for the evaluation of runners following competition. Am J Clin Pathol 2008;129:948-51.

16. Lipman GS. Clinical practice guidelines for treatment of exerciseassociated hyponatremia. Wilderness Environ Med 2013;24:466-8.

17. Rogers IR, Hew-Butler T. Exercise-associated hyponatremia: overzealous fluid consumption. Wilderness Environ Med 2009;20:139-43.

18. Rogers IR, Hoffman MD. Etiology and management of exerciseassociated hyponatremic encephalopathy (EAHE). Am J Emerg Med 2014;32:806-7

19. Wolfson $\mathrm{AB}$. Acute hyponatremia in ultra-endurance athletes. $A m \mathrm{~J}$ Emerg Med 1995;13:116-7

20. Rosner MH. Preventing deaths due to exercise-associated hyponatremia: the 2015 consensus guidelines. Clin J Sport Med 2015;25:301-2

21. Almond CS, Shin AY, Fortescue EB, et al. Hyponatremia among runners in the Boston Marathon. N Engl J Med 2005;352:1550-6.

22. Severac M, Orban JC, Leplatois T, et al. A near-fatal case of exercise-associated hyponatremia. Am J Emerg Med 2014;32:813. e1-813.e2.

23. Hew-Butler T, Boulter J, Mbchb JG, et al. Hypernatremia and intravenous fluid resuscitation in collapsed ultramarathon runners. Clin J Sport Med 2008;18:273-8.

24. Glace B, Murphy C. Severe hyponatremia develops in a runner following a half-marathon. JAAPA 2008;21:27-9.

25. Del Coso J, Salinero JJ, Lara B, et al. A comparison of the physiological demands imposed by competing in a half-marathon vs. a marathon. J Sports Med Phys Fitness 2017;57:1399-406.

26. Mohseni M, Silvers S, McNeil R, et al. Prevalence of hyponatremia, renal dysfunction, and other electrolyte abnormalities among runners before and after completing a marathon or half marathon. Sports Health 2011;3:145-51. 